\title{
Development and Evaluation of a New Push-Pull Ventilation System for Sheet-Adhesive Work Inside Bus-Body
}

\author{
Hisao YOTSUMOTO ${ }^{1}$, Yoshihisa HAYAKAWA ${ }^{2}$ and Toshihiko MYOJO ${ }^{1 *}$ \\ ${ }^{1}$ National Institute of Industrial Health, 6-21-1 Nagao, Tama, Kawasaki, 214-8585, Japan \\ ${ }^{2}$ Safetec Co., Chuorinkan 4-11-23, Yamato, Kanagawa, 242-0007, Japan
}

Received April 3, 2002 and accepted December 11, 2002

\begin{abstract}
We present the performance of a new push-pull ventilation system for sheet-adhesive work inside the body of a sightseeing coach. The target sightseeing coach was $12 \mathrm{~m}$ long, $2.5 \mathrm{~m}$ wide and $2 \mathrm{~m}$ high from floor to ceiling. We made a prototype of an airflow system and a half-scale model of the bus-body. The half scale model was $6 \mathrm{~m}$ long, $1.25 \mathrm{~m}$ wide and $0.965 \mathrm{~m}$ high. The push-pull ventilation system and half-scale model were used to evaluate the flow distributions inside the model. We also measured the concentration of xylene and methanol vapors during simulated sheet-adhesive work. As a result, it was found that the best combination was a the push flow of $24 \mathrm{~m}^{3} / \mathrm{min}$ and a pull flow of $78 \mathrm{~m}^{3} / \mathrm{min}$ in this model, and the flow velocity in the model was less than $1 \mathrm{~m} / \mathrm{s}$. This system is potentially applicable to any interior work for not only bus-bodies but also train and airplane bodies, which have elongated and confined space with many openings.
\end{abstract}

Key words: Push-pull ventilation, Bus, Sightseeing coach, Adhesive, Solvent

\section{Introduction}

Push-pull ventilation systems for painting process of passenger cars have been reported by several researchers ${ }^{1-5}$. These systems were mainly designed for removing hazardous vapors and mists from body surface of cars and not for indoor air in car-bodies. Assembly processes for the large automobiles, such as sightseeing coaches, are still handmade in contrast to processes for small passenger cars, which have been automated. Workers in bus production risk exposure to solvent vapors during adhesive work.

The push-pull ventilation system has been discussed for two decades in Japan ${ }^{6}$. People have already determined its operation conditions for small parts manufacturing. On the basis of experience, the ordinances of Ministry of Labour accepted the push-pull ventilation system for painting or welding $^{7,8)}$ as an effective ventilation system. However,

*To whom correspondence should be addressed. there are not many reports on the design of the push-pull ventilation system for large units. Confined space work, such as on bus interior preparation, also need a suitable pushpull ventilation system.

A Japanese bus-body company used synthetic leather sheets laminated with polyurethane foam for the interior walls of sightseeing coaches. The leather sheets give on impression of luxury and softness. But in the bus-body, which is semi-confined space, the workers fixed the sheets to the ceiling and walls with adhesives dissolved in organic solvents. These solvents consist of toluene, n-hexane, acetone, acetate esters and so on. In this process, one worker sprays the adhesives with a spray gun, then three workers fix the sheets to the ceiling, inner walls and window pillars, while they are wearing gas masks to protect against evaporated solvent vapor. The company has already realized the necessity of improving of the work environment but past installation of a conventional exhaust hood could not reduce the contaminants effectively. 


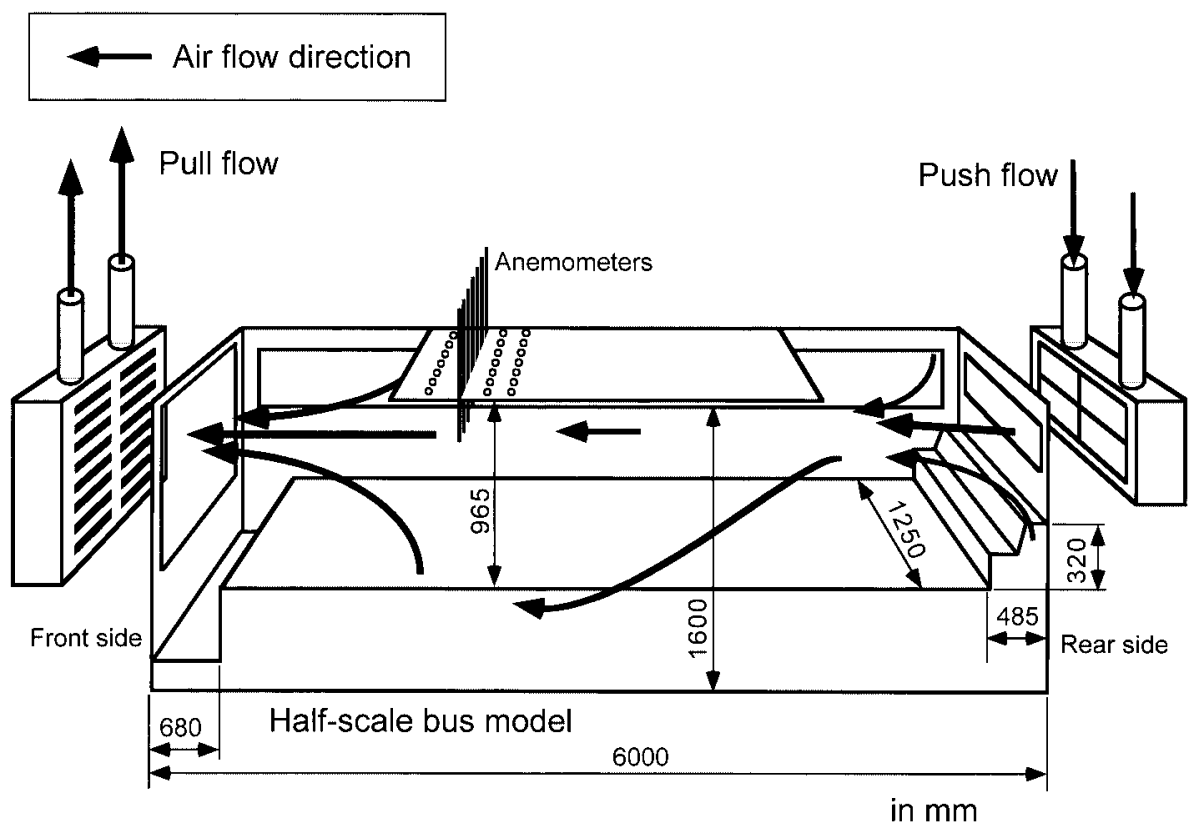

Fig. 1. Schematic diagram of the push-pull ventilation system and the half-scale model of a sightseeing coach used in this study.

In this paper, we present performance of a new push-pull ventilation system for this sheet-adhesive work in bus-bodies. We made a prototype airflow system and half-scale model of a bus-body to evaluate the flow distribution. Also we measured the vapor concentrations of $p$-xylene and methanol, as typical heavy and light molecule vapors (specific densities of $p$-xylene and methanol are 3.66 and 1.11 against air), in the model bus-body under simulated work.

A purpose of this paper is to find the best flow rates for push and pull air in this system from the results of flow visualization, measurements of flow distributions and vapor concentrations in this model. These results have been applied to the actual ventilation system for sheet-adhesive work in a bus-body.

\section{Experimental Apparatus and Procedure}

\section{Design of the ventilation system}

The real sightseeing coach considered here was $12 \mathrm{~m}$ long, $2.5 \mathrm{~m}$ wide and $2 \mathrm{~m}$ high from floor to ceiling. The front window was $2.45 \mathrm{~m}$ wide and $2.1 \mathrm{~m}$ high. The rear window was $1.9 \mathrm{~m}$ wide and $0.84 \mathrm{~m}$ high. During the interior work, all windows were not covered with windshield glasses.

In this study, we made a half scale model of the above bus. Our ventilation system supplied fresh air from the rear window (push flow) and sucked contaminated air from the front window to the outside (pull flow). Fig. 1 shows the half-scale model system, which consisted of the test airflow system and half-scale model of the bus-body. The required ventilation flow in the bus-body is uniformly distributed from front to rear and its velocity is less than $1 \mathrm{~m} / \mathrm{s}$. Workers used to complain of uncomfortableness in high flow velocity over $1 \mathrm{~m} / \mathrm{s}$.

Plenum boxes with slot openings were closely installed by the front window and rear window. The front plenum box had $8 \times 2$ slots $(0.470 \mathrm{~m}$ wide and $0.030 \mathrm{~m}$ high $)$. The velocity at each slot opening was set at around $10 \mathrm{~m} / \mathrm{s}$. The rear plenum box (four units of the opening which are 0.465 $\mathrm{m}$ wide and $110 \mathrm{~mm}$ high), through which supplied clean air, had flow guide vanes to adjust the flow direction. The guide vanes were fixed to supply air toward the ceiling of the bus-body.

The inverter motors of blowers $(0.4 \mathrm{~kW}$ for push flow and $2.2 \mathrm{~kW}$ for pull flow) controlled the flow rate in this ventilation system. The range of push flow was from 10 to $24 \mathrm{~m}^{3} / \mathrm{min}$ and that of pull flow was from 45 to $80 \mathrm{~m}^{3} / \mathrm{min}$.

The performance of this ventilation system was evaluated at the rear end and middle part (slightly toward the front) of the body. At the rear end, fresh air is supplied through the narrow rear window and then expanded throughout the whole body. Flow stagnation, which makes hot spots of contaminants, may exist in the rear space. As there was no windshield glass in the side windows and the bus-body was fairly long, the expanded air may flow out through the side 


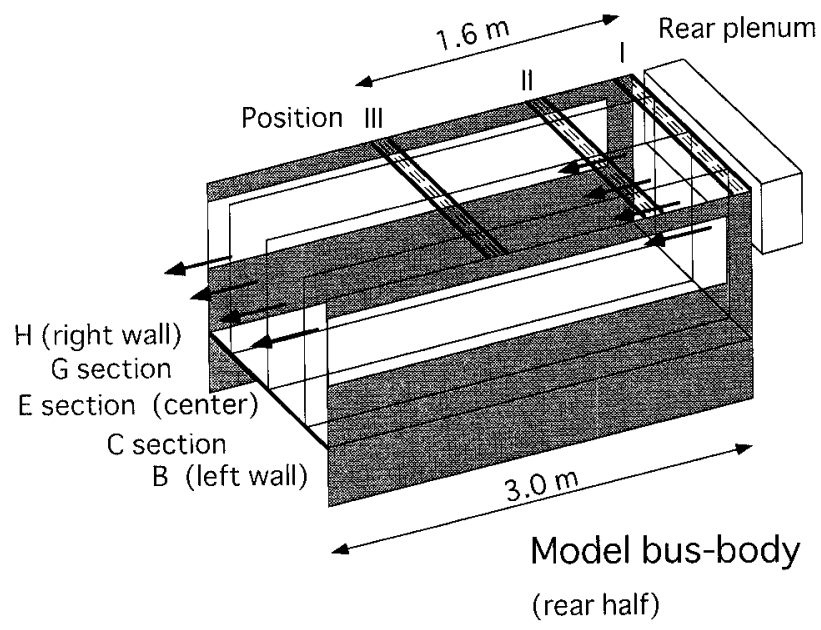

Fig. 2. Rear half of the model and the locations of urethane foam sheets as test contaminants sources.

windows. The flow rate of pull-air from the front plenum box was also important because it should remove the contaminated airflow effectively.

\section{Model of the bus-body}

The half size model of the bus-body was $6 \mathrm{~m}$ in length, $1.25 \mathrm{~m}$ wide, $1.6 \mathrm{~m}$ high and $0.965 \mathrm{~m}$ high from floor to ceiling in the bus-body. The front window was $1.2 \mathrm{~m}$ wide and $1.04 \mathrm{~m}$ high. The rear window was $0.97 \mathrm{~m}$ wide and $0.28 \mathrm{~m}$ high. On the roof of the model, there were $7 \times 29$ holes at $20 \mathrm{~cm}$ intervals for a multi-channel anemometer (see Fig. 1).

The workers risk exposure to solvent vapors from leather sheets when the are being fixed to the ceiling rather than to the side walls. On the downside of the ceiling, three urethane foam sheets of $1.23 \mathrm{~m} \times 0.20 \mathrm{~m}$ and $5 \mathrm{~mm}$ thick were fixed on by means of wire mesh screens as a simulated vapor source. The three sheets were located at the rear end, and $0.6 \mathrm{~m}$ and $1.6 \mathrm{~m}$ from the rear end, as shown in Fig. 2. For the measurement of vapor concentrations, guide strings to indicate the location were passed through the holes and fixed to floor.

\section{Measuring instruments}

The flow distribution in the bus-body was measured by means of a multi-channel anemometer (Anemomaster system 6243, KANOMAX Japan Inc. Osaka) with seven point-type sensors. The seven sensors were fixed on the bottom of seven pipes, which are connected together. The location of the sensor system was adjusted by using the roof rail of the bus-body and changing the insertion depth. The pipes through the roof holes were up and down to adjust the vertical location of measuring points (See Fig. 3).

For flow visualization, a smoke generator (Porta Smoke PS-1002, Dainiti Kougyo, Tokyo) located at the push flow inlet was used to generate tracer smoke.

Detector tubes (Gastec Co., Kanagawa) were used to measure the concentrations of organic vapors in the busbody. Xylene and methanol were used as test vapors of typical heavy and light molecules. Two minutes after soaking the urethane foam sheet in the solvent, the inlet of the detector tube was set at each guide string. The measurements at several positions around the vapor source finished within 8 minutes to ensure stable conditions.

Fig. 2 shows the locations of three sections(right, center and left or C, E and G) and three sources of organic vapor in the bus-body(rear end, $0.6 \mathrm{~m}$ and $1.6 \mathrm{~m}$ from rear end or I, II and III).

\section{Results and Discussion}

\section{Push-pull flow combination}

In order to estimate the blower capacity of this system, an equation for jet flow from a duct with guide vanes (at first, we set duct width, $d_{o}=0.15 \mathrm{~m}$ ) was used as below ${ }^{9}$.

$\mathrm{v}_{\mathrm{x}} / \mathrm{v}_{0}=\mathrm{k}_{\mathrm{x}} / \mathrm{d}_{\mathrm{o}}$

$\mathrm{v}_{0}$ : initial jet velocity,

$\mathrm{v}_{\mathrm{x}}$ : jet velocity at the distance $\mathrm{x}$ from nozzle,

$\mathrm{d}_{\mathrm{o}}$ : duct width, and

$\mathrm{k}=3.7$ (a value for maximum guide vanes angle).

When the air velocity at the front window is $0.1 \mathrm{~m} / \mathrm{s}(\mathrm{x}=6$ $\mathrm{m})$, the jet flow from the rear plenum box should be $1.08 \mathrm{~m} /$ $\mathrm{s}$ at the rear window $(\mathrm{x}=0 \mathrm{~m})$, from Equation (1). For the duct with $0.95 \mathrm{~m}$ wide, the push flow rate is $9.2 \mathrm{~m}^{3} / \mathrm{min}$. The blower for pull air should have a few times or more capacity than that for push air.

We observed the smoke patterns at several push-pull flow combinations. When the flow rates of push-pull flows were 11 and $45 \mathrm{~m}^{3} / \mathrm{min}$, the smoke spilled over through all the openings. At 18 and $55 \mathrm{~m}^{3} / \mathrm{min}$, the smoke still leaked out from the door near the front window. In order to prevent the spill of the smoke, a pull flow of $61 \mathrm{~m}^{3} / \mathrm{min}$ was needed with a push flow of $18 \mathrm{~m}^{3} / \mathrm{min}$ minimum. Finally, the flowrate of the pull flow is adjusted to $78 \mathrm{~m}^{3} / \mathrm{min}$ through the front window. For the flow-rate of push flow, 18 or $24 \mathrm{~m}^{3} /$ min through the rear window were chosen as candidates for later tests.

\section{Flow distribution in the bus model}

Figs. 4 to 9 show the velocity distributions of the flow in 
Front

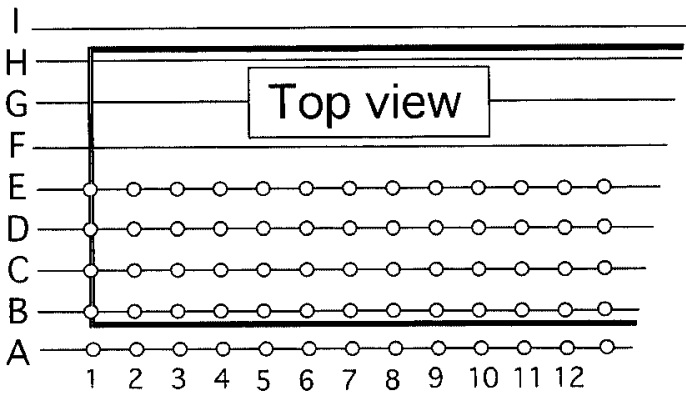

Rear

Front

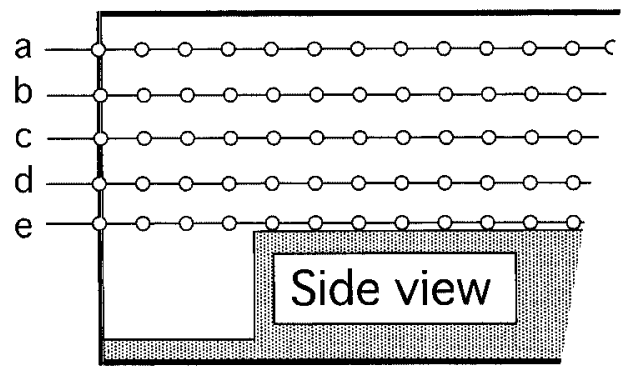

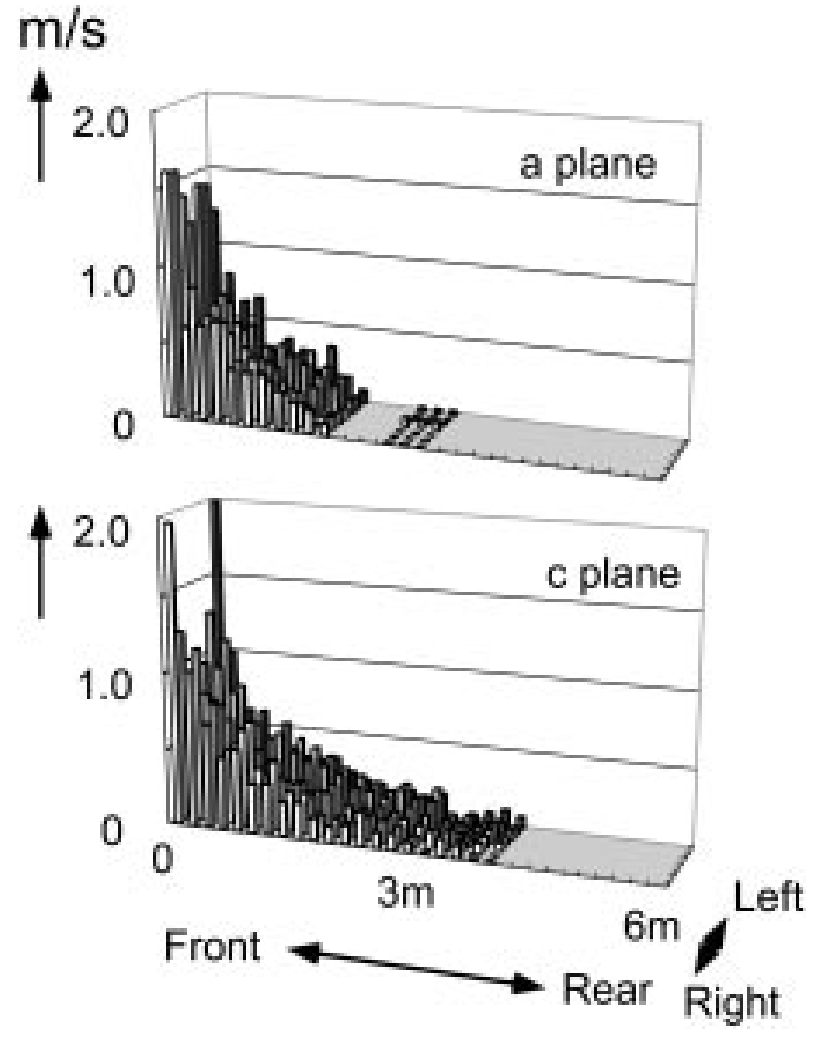

Fig. 4. Flow distribution inside bus model.

The pull flow rate was $78 \mathrm{~m}^{3} / \mathrm{min}$ without push flow. "a" plane is near the ceiling (10 cm below ceiling) and "c" plane is halfway $(50 \mathrm{~cm}$ below the ceiling) between the ceiling and floor (see Fig. 3 ).
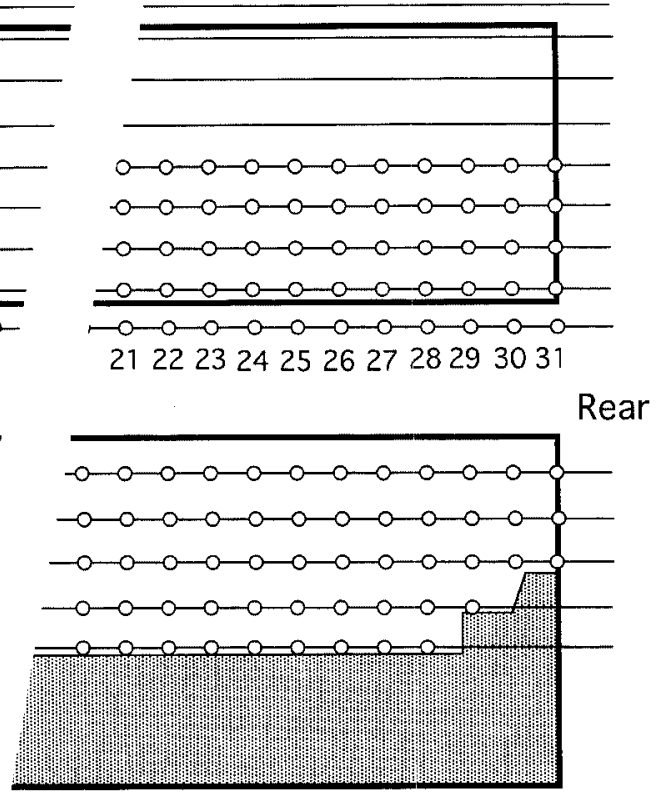

Fig. 3. Detail of sampling points around the model. Unit length in this figure is $20 \mathrm{~cm}$.

\section{$\mathrm{m} / \mathrm{s}$}
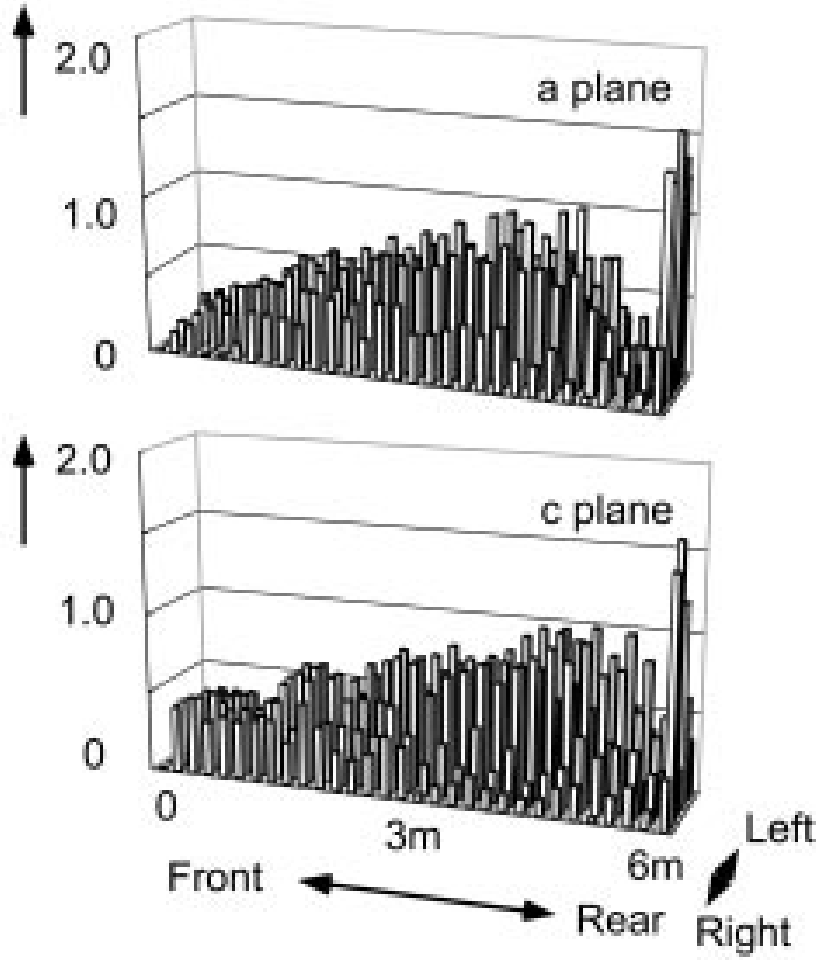

Fig. 5. Flow distribution inside bus model.

The push flow rate was $18 \mathrm{~m}^{3} / \mathrm{min}$ without pull flow. "a" plane is near the ceiling and "c" plane is halfway between the ceiling and floor (see Fig. 3). 


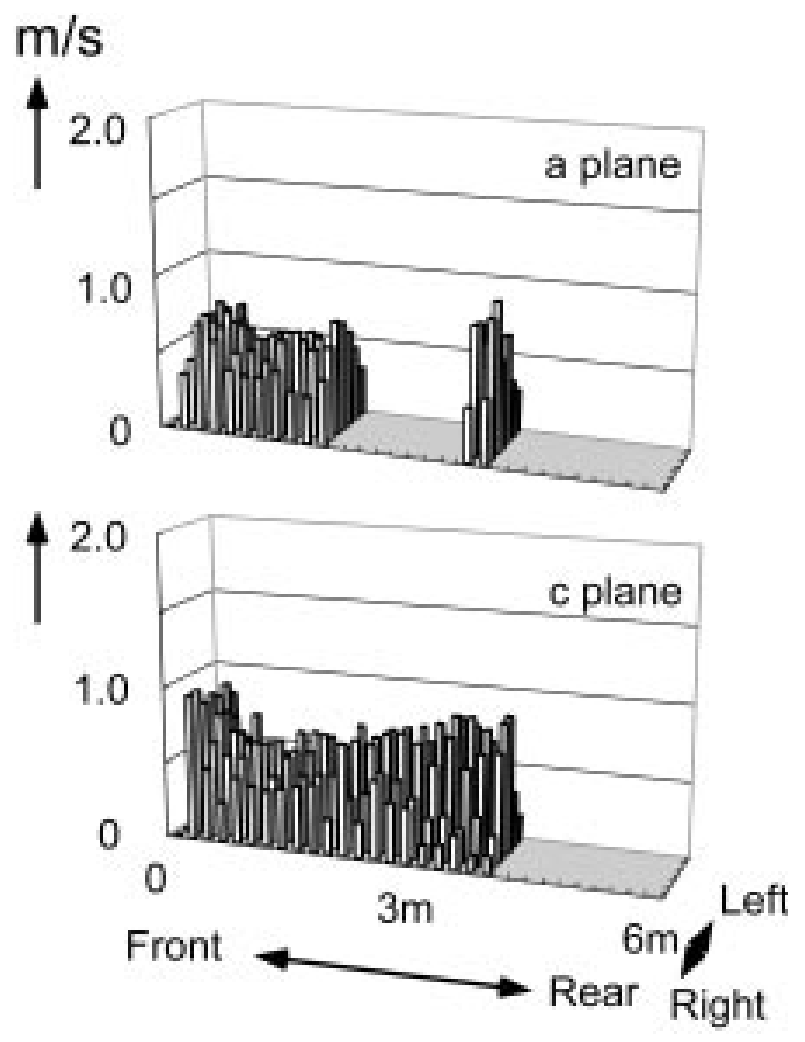

Fig. 6. Flow distribution inside bus model.

The push flow rate was $18 \mathrm{~m}^{3} / \mathrm{min}$ and the pull flow rate was $78 \mathrm{~m}^{3} / \mathrm{min}$. "a" plane is near the ceiling and "c" plane is halfway between the ceiling and floor (see Fig. 3).

the bus-body measured for pull flow only (Fig. 4), push flow only (Fig. 5 and Fig. 7), and push-pull flows (Fig. 6 and Fig. 8). As push flows set two flow rates, there are two cases: push flow only and push-pull flow.

Fig. 4 shows that the slot hood system at the front window captured the air from the center of the bus-model. The flow velocities were uniform at the center line and sidewalls of the bus. It performs as well as a normal hood.

Fig. 5 and Fig. 7 show the flow distributions in the busbody for push flow only at 18 or $24 \mathrm{~m}^{3} / \mathrm{min}$. At the rear end, fresh air was supplied through the narrow rear window and then expanded to the whole body. The flow distribution near the rear window was not uniform.

Fig. 6 and Fig. 8 show the flow distributions in the busbody for push flow at 18 or $24 \mathrm{~m}^{3} / \mathrm{min}$ with pull flow at 78

Fig. 8. Flow distribution inside bus model.

The push flow rate was $24 \mathrm{~m}^{3} / \mathrm{min}$ and the pull flow rate was $78 \mathrm{~m}^{3} / \mathrm{min}$. "a" plane is near the ceiling and "c" plane is halfway between the ceiling and floor (see Fig. 3).
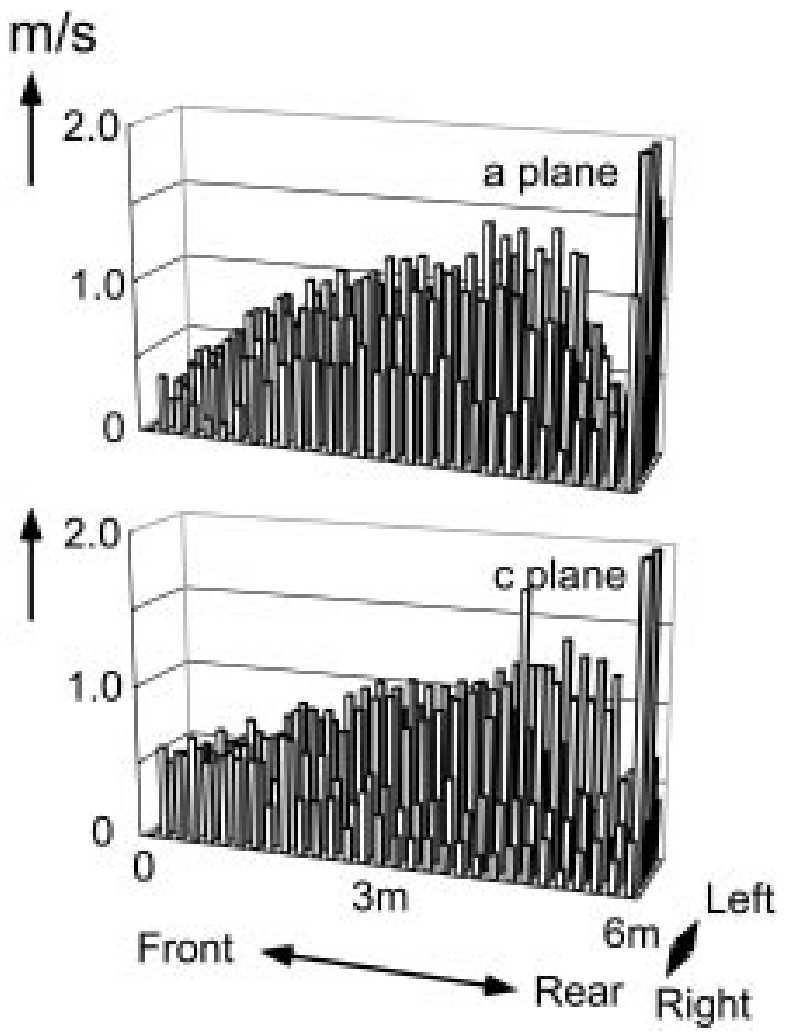

Fig. 7. Flow distribution inside bus model.

The push flow rate was $24 \mathrm{~m}^{3} / \mathrm{min}$ without pull flow. "a" plane is near the ceiling and "c" plane is halfway between the ceiling and floor (see Fig. 3).

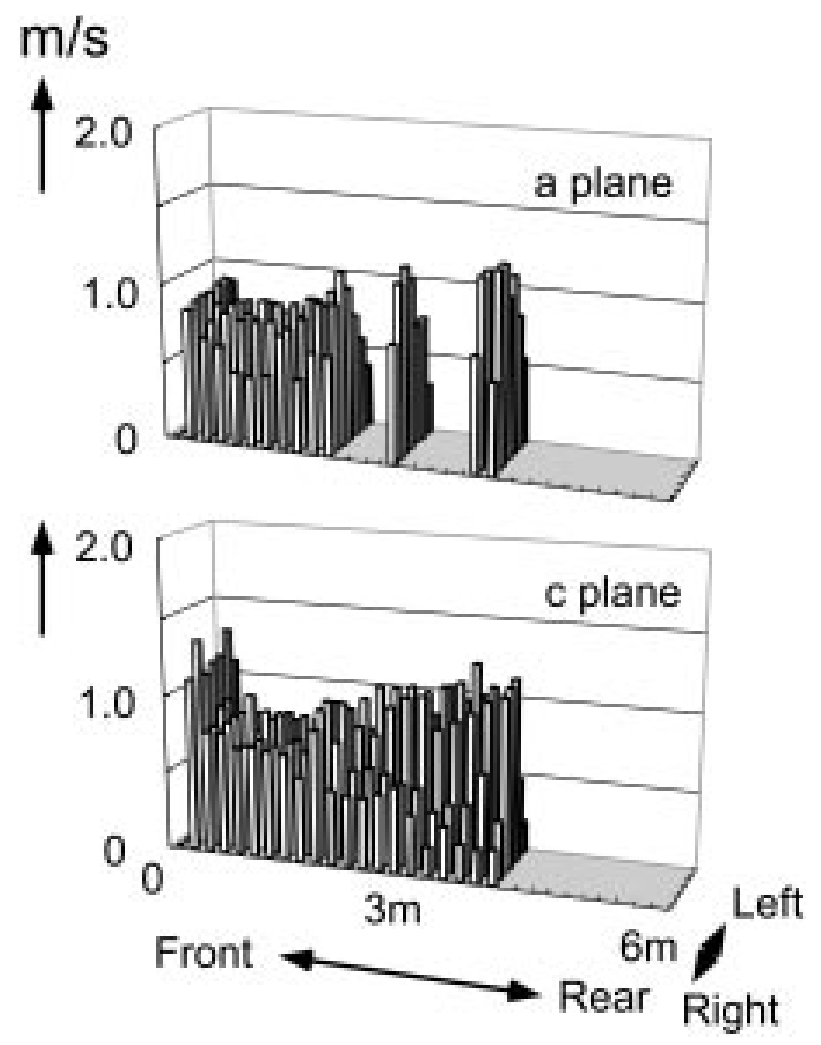



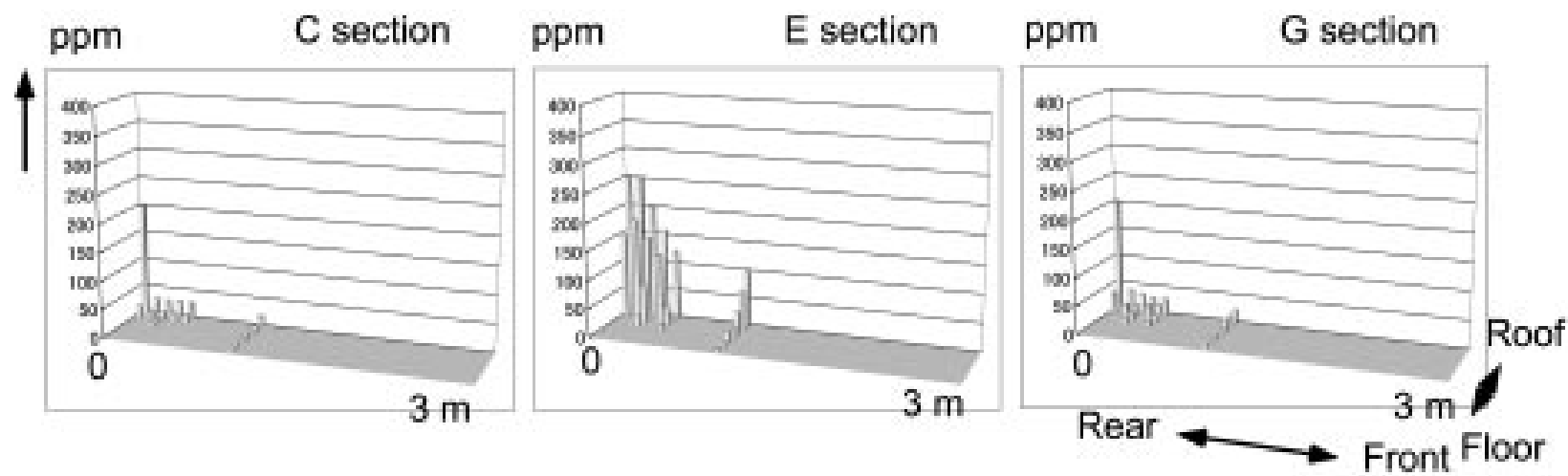

Fig. 9. Vapor concentrations of xylene inside bus model.

The location of the test contaminants source is I in Fig. 2. The sections $\mathrm{C}, \mathrm{E}$ and $\mathrm{G}$ also correspond to these sections in Fig. 2. Unit length on each section is $10 \mathrm{~cm}$. The push flow rate was $24 \mathrm{~m}^{3} / \mathrm{min}$ and the pull flow rate was $78 \mathrm{~m}^{3} / \mathrm{min}$.

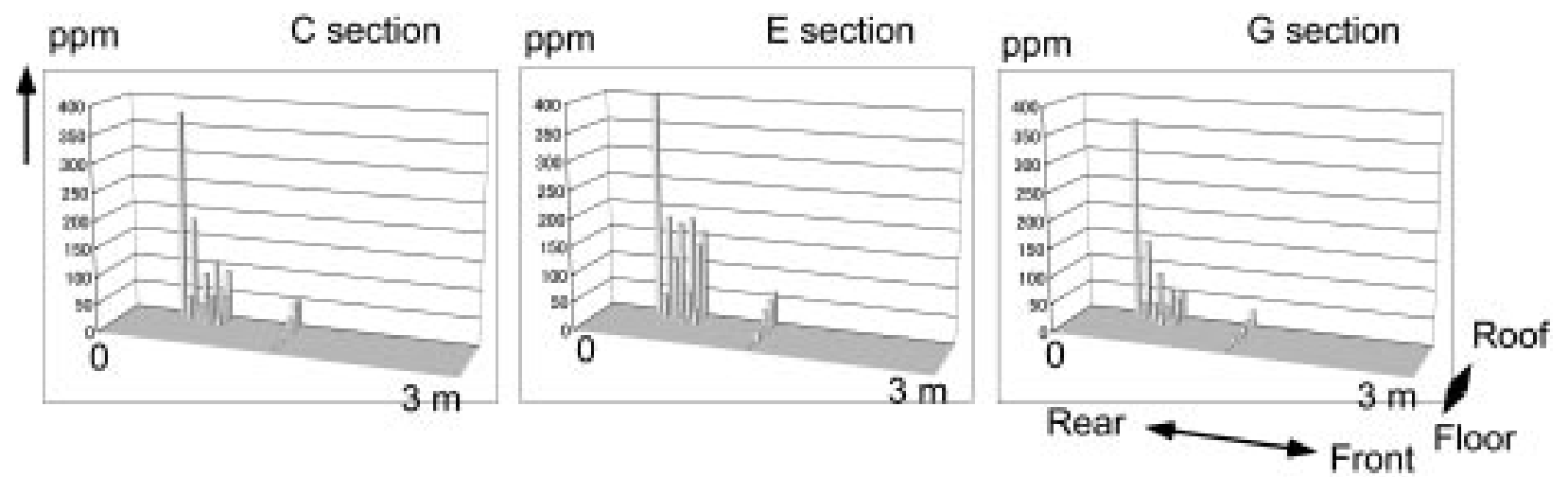

Fig. 10. Vapor concentrations of xylene inside bus model.

The location of the test contaminants source is II in Fig. 2. The sections C, E and G also correspond to these sections in Fig. 2. The push flow rate was $24 \mathrm{~m}^{3} / \mathrm{min}$ and the pull flow rate was $78 \mathrm{~m}^{3} / \mathrm{min}$.

$\mathrm{m}^{3} / \mathrm{min}$. In order to see the push-pull effect, we focused on the middle part (slightly to the front) of the body in this measurement. The flow distributions at the rear end were not measured simultaneously because these were similar to those shown in Figs. 5 and 7. Although there was no windshield glass in the side windows and the bus-body was fairly long, flow velocity was uniform in the longitudinal direction in the bus. At $18 \mathrm{~m}^{3} / \mathrm{min}$ of push flow, the flow velocity near the middle part was about $0.5 \mathrm{~m} / \mathrm{s}$, and at 24 $\mathrm{m}^{3} / \mathrm{min}$ the velocity was about $0.8 \mathrm{~m} / \mathrm{s}$. The front plenum box for pull flow could collect the contaminated airflow effectively.

\section{Distribution of test contaminants in the bus model}

At the rear end, fresh air was supplied through the narrow rear window and then expands throughout the whole body. Flow stagnation in the space may make hot spots of contaminants. The concentrations of $p$-xylene and methanol vapors in the bus-body were measured with detector tubes. Figs. 9-11 show the concentrations of xylene vapor at the three sources in the bus-body. The flow conditions for this measurement were $24 \mathrm{~m}^{3} / \mathrm{min}$ for push flow with $78 \mathrm{~m}^{3} /$ min for pull flow.

At the rear end, the push flow introduced side flows through side windows and made flow circulation. In Fig. 9, we can see that the xylene vapor stayed in the center part (E section) but side flows diluted the concentration of the contaminants rapidly in the $\mathrm{C}$ and $\mathrm{G}$ sections.

On the other hand, when the vapor source was located at $1.6 \mathrm{~m}$ from rear end, xylene vapor stayed in each section and was at a high concentration, as shown in Fig. 11. Partly, the expanded air with the vapor may flow out through the side windows.

Fig. 12 shows concentrations of methanol vapor when 

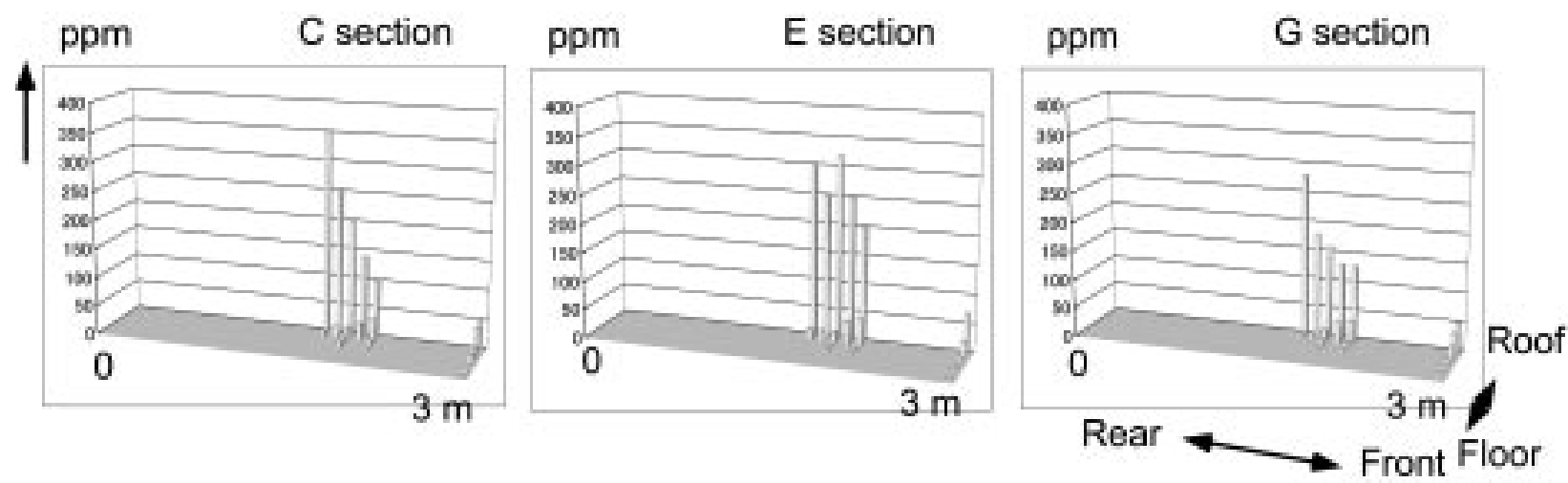

Fig. 11. Vapor concentrations of xylene inside bus model.

The location of the test contaminants source is III in Fig. 2. The sections C, E and G also correspond to these sections in Fig. 2. The push flow rate was $24 \mathrm{~m}^{3} / \mathrm{min}$ and the pull flow rate was $78 \mathrm{~m}^{3} / \mathrm{min}$.

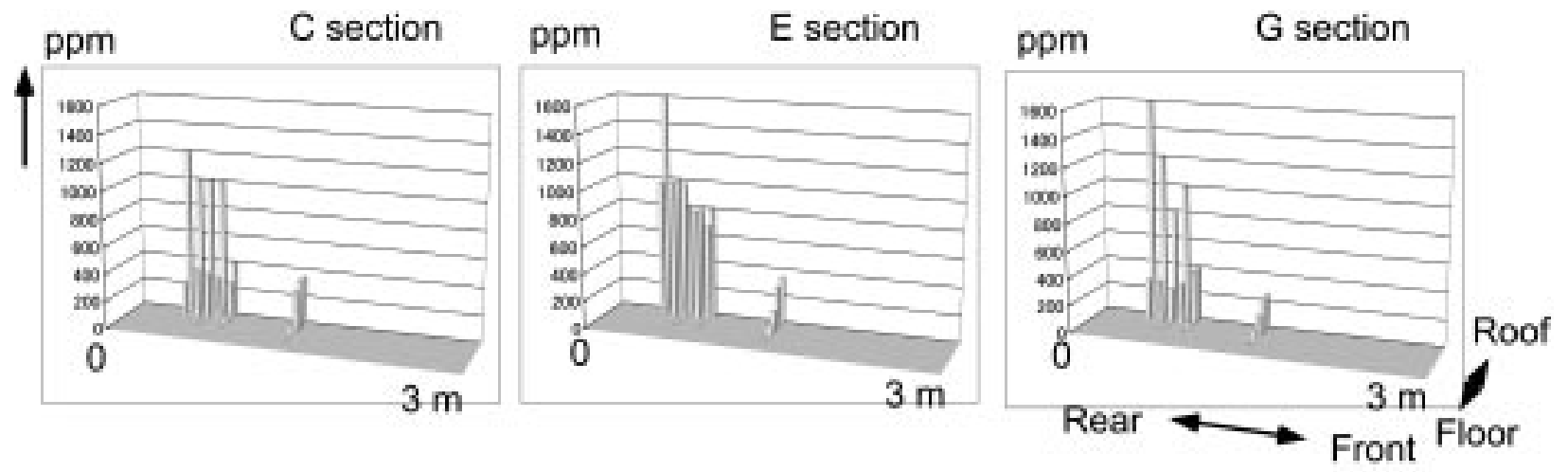

Fig. 12. Vapor concentrations of methanol inside bus model.

The location of the test contaminants source is II in Fig. 2. The sections C, E and G also correspond to these sections in Fig. 2. The push flow rate was $24 \mathrm{~m}^{3} / \mathrm{min}$ and the pull flow rate was $78 \mathrm{~m}^{3} / \mathrm{min}$.

the source was located at $0.6 \mathrm{~m}$ from the rear end (II at Fig. 2). This figure and Fig. 10 have the same location for the vapor source. Methanol vapor did not diffuse to the floor as did xylene vapor. We detected only xylene vapor near the floor position at $1 \mathrm{~m}$ downstream because of the specific density difference.

Because of limited manpower, we could not measure vapor concentrations at all the interesting points. Figs. 9-11 show only specific points and do not detail vapor distributions throughout the model. By introducing enough of detector tubes or real-time gas sensors, vapor distribution will be clarified in future studies.

These data on the flow velocity distributions and vapor concentrations (Figs. 4 to 12) show that push flow made contaminants sweep off and dilute with side flow air. We can expect a good work environment for workers inside the bus-body, if they work from front to rear in the bus with leather sheets and adhesives. In this study, we did not take into account the effect of workers who also disturb the flow in the bus body. Therefore, personal exposure assessments for the workers will confirm whether wearing gas masks is necessary or not.

\section{Conclusion}

A new push-pull ventilation system was developed for sheet-adhesive work in a bus-body. We found a best operation condition in which the push flow was $24 \mathrm{~m}^{3} / \mathrm{min}$ and the pull flow was also $78 \mathrm{~m}^{3} / \mathrm{min}$ in this model. This system is potentially applicable to any interior work for elongated and confined space with many openings.

The real-scale ventilation system has been installed in the company. They used this system at the flow conditions of $40 \mathrm{~m}^{3} / \mathrm{min}$ for push flow and $186 \mathrm{~m}^{3} / \mathrm{min}$ for pull flow. 
As an additional improvement in the workplace, a small and relocatable push-flow-box connected to flexible duct was set on the floor of an actual bus-body to eliminate flow stagnation in the rear space.

\section{References}

1) Goyer N (1995) Performance of painting booths equipped with down-draft ventilation. Am Ind Hyg Assoc J 56, 258-65.

2) Heitbrink WA, Wallace ME, Bryant CJ, Ruch WE (1995) Control of paint overspray in autobody repair shops. Am Ind Hyg Assoc J 56, 1023-32.

3) Heitbrink WA, Verb RH, Fischbach TJ, Wallace ME (1996) A comparison of conventional and high volumelow pressure spray-painting guns. Am Ind Hyg Assoc J 57, 304-10.

4) Carlton GN, Flynn MR (1997) Influence of spray painting parameters on breathing zone particles size distribution. Appl Occup Environ Hyg 12, 745-50.

5) Flynn MR, Gatano BL, McKernan JL, Dunn KH, Blazicko BA, Carlton GN (1999) Modeling breathingzone concentrations of airborne contaminants generated during compressed air spray painting. Ann Occup Hyg 43, 67-76.

6) Hayashi T, Shirakawa M, Mori Y (1987) Important problems on a booth and the solution. Safety Digest 34, 167-71 (in Japanese).

7) Ordinance on the prevention of organic solvent poisoning. The Ministry of Labour Ordinance, 1997.

8) Ordinance on the prevention of hazards due to dust. The Ministry of Labour Ordinance, 1998.

9) Kuuki Tyouwa Handbook (Air conditioning handbook). 3rd ed, eds. by Inoue U, 259 Maruzen, Tokyo, 1980 (in Japanese). 